\title{
Correction to: Synchronized broadcast spawning by six invertebrates (Echinodermata and Mollusca) in the north-western Red Sea
}

\author{
Alice E. Webb ${ }^{1}$. Aschwin H. Engelen ${ }^{2}$. Jessica Bouwmeester ${ }^{3,4}$. Inge van Dijk ${ }^{5}$. Esmee Geerken ${ }^{1}$. Julie Lattaud ${ }^{6}$. \\ Dario Engelen $^{9} \cdot$ Bernadette S. de Bakker $^{7} \cdot$ Didier M. de Bakker ${ }^{8}$ (D)
}

Published online: 22 May 2021

(c) The Author(s) 2021

\section{Correction to: Marine Biology https://doi.org/10.1007/s00227-021-03871-6}

In the original publication of the article, The affiliation of author Dario Engelen was incorrectly published. The correct affiliation is Escola Secundária de Loulé, Avenida Laginha Serafim, 8100-740 Loulé, Portugal.

The original article has been updated.

Publisher's Note Springer Nature remains neutral with regard to jurisdictional claims in published maps and institutional affiliations.

The original article can be found online at https://doi.org/10.1007/ s00227-021-03871-6.

Didier M. de Bakker

didierdebakker@gmail.com

1 Department of Ocean Systems, NIOZ-Royal Netherlands Institute for Sea Research, and Utrecht University, 1790 AB Den Burg, The Netherlands

2 Centro de Ciências Do Mar Do Algarve (CCMAR), University of Algarve, 8005139 Faro, Portugal

3 Smithsonian Conservation Biology Institute, National Zoological Park Department, Front Royal, VA 22630, USA

4 Hawaii Institute of Marine Biology, Kaneohe, HI 96744 , USA
Alfred-Wegener-Institut, Helmholtz-Zentrum Für Polar-Und Meeresforschung, 27570 Bremerhaven, Germany

6 Biogeoscience Group, ETH Zurich, 8092 Zurich, Switzerland

7 Department of (Neuro)Pathology, Amsterdam UMC, University of Amsterdam, 1105AZ Amsterdam, The Netherlands

8 Wageningen Marine Research, Wageningen University and Research, 1780 AB Den Helder, The Netherlands

9 Escola Secundária de Loulé, Avenida Laginha Serafim, 8100-740 Loulé, Portugal 